\title{
ERRATUM
}

Hermann P. G. Schneider • Christian Jackisch

\section{Endocrine management of breast cancer-biology and current practice}

Published online: 20 August 2005

(C) European Board and College of Obstetrics and Gynaecology 2005

\section{Eur Clinics Obstet Gynaecol (2005) 1:102-114}

This paper was published under the section heading "Original Paper". It should have been a "Clinical Review".

The online version of the original article can be found at http:// dx.doi.org/10.1007/s11296-005-0016-3

H. P. G. Schneider $(\bowtie)$

Department of Obstetrics \& Gynaecology, University of Muenster, Von-Esmarch-Str. 56, ZMBE, 48149 Muenster, Germany

E-mail: HPG.Schneider@uni-muenster.de

Tel.: + 49-251-8355710

Fax: +49-251-8355711

C. Jackisch

Department of Gynaecology, University of Marburg,

Pilgrimstein 3, 35037 Marburg, Germany

E-mail: jackisch@med.uni-marburg.de 